\title{
On black children in black families
}

\section{[ B O O K REVIEW ]}

Makiwane, Monde, Nduna, Mzikazi \& Khalema, Nene, E (eds) (2016) Children in South African families: Lives and times. Newcastle-upon-Tyne: Cambridge Scholars Publishing. ISBN 9781443897358 hbk. Pages 320

Theorising healthy development of children, identifying troubling "obstacles" to their thriving, and intervening in appropriate ways to support and monitor wellbeing is never neutral work. Over the years, given the inequities and injustices of colonial and apartheid apparatuses in South Africa, there has been a lot of attention given - by social scientific academics, researchers, activists and policymakers - to children and families. This attention has focused most notably on black children and families, living in everyday conditions of adversity, vulnerability and risk, and has incorporated various theoretical lenses and advocacy for interventions. It would be somewhat of an understatement to say that a complex (discursive) forcefield embeds children, childhoods and adolescence in South Africa. Many social scientific signpost-texts in this field are positioned in that community-coalface place of theorising issues in evidence-based ways and pushing transformation along social justice lines (e.g. Burman \& Reynolds, 1986; Dawes \& Donald, 1994; De la Rey, Duncan, Shefer \& Van Niekerk, 1997; Donald, Dawes \& Louw, 2000; Dawes, Bray \& Van der Merwe, 2007; Bray, Gooskens, Kahn, Moses \& Seekings, 2010). While many of these texts actively engage with (black) families and

\section{Lindy Wilbraham}

Psychology Department

Rhodes University

Grahamstown

L.Wilbraham@ru.ac.za 
custodial arrangements around children, there are also a number of new texts on socalled "teenage pregnancy", fatherhood and (African) masculinities.

Into the fray comes Children in South African families: Lives and times, and attention inevitably shifts from the table of contents to the introductory and concluding chapters, looking for its premises and framing. How do its editors argue for its place in a crowded market of competing knowledges about black families in South Africa? Several of its territory markers direct a path towards the diversity of family formations and caregiving of young people, which contextualize parenting and children's experiences. Against the homogenizing effects of industrial capitalism on family structures that allegedly finds black families "teetering towards the conventional white [nuclear] family structure" ( $p$ xvii), the introductory chapter (Makiwane, Khalema, Gumede \& Nduna) promises to locate, accept and affirm the diversity of family structures in Africa, and to forge an understanding of changing family life in transitional democracies like South Africa. In this task, the book will eschew nostalgia - namely, the simplistic assumption that modernism has undermined traditional African values - and it proclaims (against ubuntu rhetoric) that "the days when the extended family and the community worked in unison are gone" ( $p$ xviii). Instead, it promises to use primary and secondary data sources to illustrate how resilience in children within diverse African social and cultural contexts could be nurtured, and to explore links between theory and practice, informed by a social justice framework. Thus, the focus is exclusively on black South African children, and the book's chapters are organised around four familiar themes - family structure and childbearing, parenting, fatherhood and support for children.

Later on, in the concluding chapter of the book (Khalema, Vawda, Ndinda \& Makiwane), it is claimed that "a new social scientific approach to children as a social phenomenon" has been posited, namely, "a critical African-focused and justice-based perspective infused with a life course approach" ( $p$ 307). This claim was dismissive or naïve of the decades of scholarship, evidence, intervention and activism in this expertcrowded space around black children and their families; and it set my hackles up. It was quite hard work to find the promised innovation in, or coherence between, the chapters of this book. How were themes decided on, and authors chosen for individual chapters? Authors appeared from various formal positions across interdisciplinary social scientific academic and public health research institutions, or joint projects in between these (e.g. the Father Connection project); and funding for the book from the DST-NRF Centre of Excellence in Human Development was acknowledged. While this authorial and institutional diversity added breadth to the book, it also challenged the coherence - and overall usefulness and applicability - of the writing for different audiences. There was unevenness between the chapters in terms of tone, aims and 
depth; some concepts (such as resilience) were mostly too loosely used; and the exclusions of issues and topics were disconcerting. While twists, bumpiness and potholes in the path through the contested territories of childhoods might be expected, stronger introductory and concluding arguments might have framed these better. An index might have helped with thematic coherence of issues across bitty chapters, or finding and tracking arguments.

What follows is an account of my scrambling through and making sense of chapters of Children in South African families - not necessarily in a linear or exhaustive way. The book kicked off with several key expository chapters that sought to set up frameworks and "review" issues for understanding structures of (black) families. For example, Chapter 1 (Pillay) presented a history-of-the-present of children's rights in South African families, and the imperatives for a social justice perspective, amidst various challenges such as the negative effects of poverty and HIV/Aids, poor State support for families and deleterious African cultural practices. Chapter 2 (Makiwane, Gumede \& Molefi) tackled the roles - in sociohistorical perspective, finding continuity and change - of relationships, marriage, childbearing and the constitution of households in which children live. The latter chapter, too briefly, in about 12 pages of narrative, presented declining marriage, unsupportable pregnancies (especially among younger women), the use of contraception, multiple and concurrent sexual partnerships, and the "resurgence" of cultural practices, such as virginity-testing. These are complex issues which have attracted large amounts of research and writing, and the descriptive, dated and scanty review - albeit "Africanfocused" - barely skimmed the surfaces. Perhaps such chapters were put into the book as defensive placeholders, to demonstrate the sweep of issues that would not necessarily be focused on in-depth?

Continuing to set the scene, Chapter 4 (Ndagurwa \& Nzimande) presented a detailed multivariate regression study on the impact of various "family structures", socioeconomic resources available to households and provincial location, on different schooling outcomes for children in South Africa. Findings confirmed previous research from South Africa, and sub-Saharan Africa more generally: children living in nuclear families tend to do better in schooling outcomes than other types of family formations, because of better socioeconomic resources and monitoring this afforded children. If socioeconomic status (e.g. household income) was controlled, children living in woman-headed households (e.g. single-parent, skipped-generation or three-generation) had similar outcomes to those from nuclear families; but province of school enrolment, and rural-urban dimensions of household locations, also affected children's schooling success. These findings were not new or surprising; but it was surprising that Children in South African families 
allowed this chapter to balloon to 56 pages of positivist-statistical detail - whereas other chapters were limited to an average 15 pages each and sometimes suffered from this imposed brevity. The length of Chapter 4 conferred undue importance to a study which scrambled somewhat in tasking the State with better social welfare protection and improved quality of education for all children, to support the value placed on diversity of family formations. One had a distinct sense that this chapter was cut and pasted from its original form elsewhere.

The meat, and heart, of this text undoubtedly lies in its contributions to parenting dynamics and discourse, particularly in its sustained attention to fatherhood, or dimensions of fatherlessness. The freshness of work in this theme of the book lay in the diversity of theoretical lenses that appeared. Highlights of this richness (for me) included these examples. Chapter 5 (Rabe) re-examined the assumed differences in the gendered discourse on parenting - between fatherhood and motherhood - in the feminist light of Andrea Doucet's critical reading encouragement to "examine the difference that difference makes" ( $p$ 117). Chapter 9 (Lesch \& Scheffler) explored the need for research on father-daughter relationships in South Africa along the lines of how this relationship has been constructed through psychoanalytic, feminist and social constructionist perspectives. Chapter 11 (Mdletshe) presented an empirical study that investigated the coping strategies and resilience of young women with absent fathers in Soweto; and here, a much-needed, thorough-going and critical examination of (theories of) resilience emerged. Of course, the uneasy imperatives of black young people's resilience, stoicism, perseverance and hope - in a book about black children, in the contexts of routine poverty and unrelenting adversities in post-apartheid South Africa - remain.

The subtitle of Children in South African families is "lives and times", which figured contexts for children's experiences. Another source of richness (for me) were the chapters that eschewed the abstract review and recommendations format, and presented primary research studies. These chapters created their own contexts through situated findings, diversity of experience on the ground, and particular praxes in terms of theories and methods. Furthermore, these original studies let readers hear and see the voices of young people themselves - rather than a whole lot more of (well-meaning) talking or writing about them - and touched on the sometimes tricky engagements (for young people) with public health interventions and help-seeking. For example, Chapter 7 (Siswana) examined amaXhosa initiation rites into manhood, associated with circumcision, and the quoted extracts describe the ecstatic physical and emotional resonance in proclaiming "Ndiyindoda" (I am a man)(p 171). But this space of cultural masculinity socialisation was critically opened up - in Chapter 7 (Siswana), and in a companion Chapter 8 (Howard-Payne 
\& Bowman) - as holding many fraught voices, contradictory positions and choices for boys/men. This includes cultural discourses about tradition (through fathers' expectations for their sons), public health discourses on medicalised circumcision as a risk-reduction technology, and feminist discourses that are suspicious of patriarchies. Similarly, Chapter 12 (Nduna) explored the competing perils of dysfunctional psychosocial support services, parental resistance and denials, and social stigma, for young women in distress, in the Butterworth district of the Eastern Cape. These studies were complex with difficult questions and experiences that did not have easy answers or neat resolutions. To their credit, they remained open to the diversity they encountered.

Diversity was not always embraced as a good thing in Children in South African families; or, perhaps the relativism and messiness of diversity cannot always be tolerated when evidence of "risks" accelerate? How do we reconcile the dilemmas that arise when some family practices are seen as 'better' than others? I will unfairly single out one example of how a rigorous review of secondary sources became skewed towards interventions to regulate diversity. I also confess my own stake here as a published and active scholar in this field. Chapter 6 (Jama-Shai \& Mdanda) examined intergenerational communication about sex and sexuality in the South African and African context/s. A familiar public health discourse undergirds the standard, stepwise, evidence-based argument which is rehearsed - (1) establish why a particular kind of parent-child communication about sex is the preferred gold standard of behaviour; (2) establish what communicating is done by whom, how, and what the barriers to the gold standard are; and then, (3) undo the barriers via appropriate interventions with (reluctant, anxious, ignorant or inept) black parents. My critical characterisation is controversial, of course, because everyone including me knows that parent-child communication about sex is important: it naturalises and socialises sex; it reduces risk; it models frank talking about needs and safeties; it teaches values. But could we ask different questions to open up spaces for difference, resistance, uncertainty, multivocality, and other difficult topics besides sex - such as talking about privilege, death, bullying or money? Is there a life to be lived beyond "the facts of life"? Would our African sky fall if we let parents off the hook?

Mothers have carried the work of communication with children about sex, and this is obliquely dealt with in Chapter 6's interpellation of "parents" - as the politically correct and wholly appropriate sharing out of this onerous responsibility, if fathers were nearby. I found myself thinking about mothering a lot, and worrying at its marginality, as the book's strong focus on fatherhood and father-absence gathered force. Motherhood does appear here and there, in fragmented glimpses, as do various ways of "doing family" other than idealized nuclearity; but these are not 
foregrounded, fleshed out or sufficiently unpacked. Chapter 10's (Manyathshe) mothers were figured as scrambling to restore "absent fathers" as a positive fatherly presence to children's lives. Research that uncritically sticks to this gold standard despite evidence of household diversity neglects to address mothering that is done in various woman-headed, three-generation or skipped-generation, arrangements - that may, for several reasons, choose freedom from troubling spouses and troubled fathers (e.g. see Moore, 2013). Chapter 3's (Pillay) worthy focus on child-headed households dispensed with mothers and fathers entirely. Can mothering and fathering of children and young people only be done by mothers and fathers? The concluding chapter (Khalema, Vawda, Ndinda \& Makiwane) rightly argued that any focus is selective, and mentioned "migrancy" experiences in South African households due to war, poverty or xenophobia as an inadvertent exclusion (p 309). Indeed, yes. A sustained gaze on motherhood and mothering practices in resource-poor conditions is also a significant gap, but perhaps that critical discourse is always-already happening elsewhere.

Children in South African families has its moments of insight - even within its embeddedness in a crowded and contested knowledge-space. The original empirical studies presented, and theoretical tools honed, were useful, and they jostled against the decontextualized, summarized, "text-book" chapters. For critical readers, this jostling presented premises for debates about/in the crossover space between academic and public health discourse. I hope the book will find readers across levels, disciplines and institutions, and its appearance in hardcover, published by Cambridge Scholars Publishing in the United Kingdom, and currently priced at $£ 60$ (via Amazon) or R2109 (via Loot) per copy, will not limit its accessibility to its African locations, arguments and resonances. I am not optimistic.

\section{References}

Bray, R, Gooskens, I, Kahn, L, Moses, S \& Seekings, J (2010) Growing up in the new South Africa: Childhood and adolescence in post-apartheid Cape Town. Cape Town: HSRC Press.

Burman, S \& Reynolds, P (eds) (1987) Growing up in a divided society: The contexts of childhoods in South Africa. Johannesburg: Ravan Press.

Dawes, A, Bray, R \& Van der Merwe, A (eds) (2007) Monitoring child well-being: A

South African rights-based approach. Cape Town: HSRC Press. 
Dawes, A \& Donald, D (eds) (1994) Childhood and adversity: Psychological perspectives from South African research. Cape Town: David Philip.

De la Rey, C, Duncan, N, Shefer, T \& Van Niekerk, A (1997) Contemporary issues in human development: A South African focus. Johannesburg: Thomson Publishing.

Donald, D, Dawes, A \& Louw, J (eds) (2000) Addressing child adversity. Cape Town: David Philip.

Moore, E (2013) Transmission and change in South African motherhood: Black mothers in three-generational Cape Town families. Journal of Southern African Studies, 39(1), 151-170. 